\title{
The Effect of Augmented Reality in Improving Visual Thinking in Mathematics of 10th-Grade Students in Jordan
}

\author{
Dr. Fadi Abdul Raheem Odeh Bani Ahmad \\ Assistant Professor of Education Technology \\ Middle East University, Amman \\ Jordan
}

\begin{abstract}
Augmented reality is one of the key issues in the area of improving visual thinking in science courses such as Mathematics. Augmented reality also offers a significant and effective role in the educational process. The current study aimed to investigate the effect of augmented reality in improving visual thinking of 10th-grade students in mathematics in Jordan. To achieve the objectives of the study, the methodology used includes the application of the semi-experimental approach and augmented reality technology. The methodology used also includes preparing a test to measure visual thinking comprising (20) multiple-choice items used as a pre-and post-test, and its validity and reliability are verified. The study sample consists of (57) female students purposefully selected from the 10th-grade students at the Jerash Model Schools for the first semester of $2020 / 2021$. The study sample is divided into two groups as follows: one is an experimental group consisting of (28) female students taught by the augmented reality technology, and the second is a control group consisting of (29) female students taught in the traditional method. The results of the study show that there are statistically significant differences at the level of ( $\alpha$ $=0.05$ ) in the development of visual thinking in favor of the experimental group students taught by the augmented reality technology. The study also shows that there are differences in the performance of the experimental group students in each skill of visual thinking.
\end{abstract}

Keywords-Augmented reality technology; visual thinking development; 10th grade; mathematics

\section{INTRODUCTION}

Augmented reality offers a significant and effective role in the educational process because it is one of the up-to-theminute and developed technological innovations that depend on smartphones. Augmented reality enables the student to deal with an imaginary or near-reality environment based on simulation between the student and a third-dimensional electronic environment because education is one of the areas strongly affected by technology and digitization.

At present, school and university students no longer want to learn by reading books and copying texts, but rather wish to exploit the advantages of technology for use in the classroom. Therefore, augmented reality has emerged as a development of virtual reality that requires special tools and professionalism for third-dimensional design programs. The augmented reality can be attained by less professional programs, or by using online libraries that contain a lot of previously designed third shapes. Moreover, augmented reality in the classroom contributes to making students busier with the curriculum, learning more deeply, and interacting and cooperating better. It is indicated that augmented reality furnishes the learners with multiple options in representing information dynamically and quickly, helping to increase learners' motivation, and developing their academic achievement [1]. Augmented reality is a form of technology that enhances the real world by merging the textbook with technology, especially a mobile phone. From the viewpoint of emphasizing the educational theories in the domain of educational technology on the significance of using visual thinking and its various tools such as images, shapes, graphs, and diagrams in the education process, this study investigates the possibility of the effect of augmented reality technology in the development of visual thinking among students during the educational learning process.

Augmented reality has always provided a significant and effective role in the educational process because it is one of the contemporary and developed technological innovations that depend on smartphones. With that, an investigation is conducted by the researchers to explore how to address the poor achievement of 10th-grade students in mathematics by interviewing several teachers. The results of the investigation show that the reason for the poor achievement of 10th-grade students is the stagnation that characterizes mathematics and is reflected in the difficulty faced by students in understanding and recognizing the content, and this is evidenced by their low achievement and motivation towards learning in general and learning mathematics in particular. Accordingly, it is necessary to move towards learning that simplifies the presentation of scientific content and lessons in a manner that meets their desires and takes into account their differences, so augmented reality is the choice from the researchers' point of view because it does not require effort, time, and cost to enhance, enrich, and support the environment of the educational learning process. In light of the recommendations of the study, it is noted that augmented reality motivates students to conduct interactive experiments and develops their visual thinking [2]. Also, it is maintained that augmented reality is used in Japan and Austria in the museums of mathematics and science to develop remembering and prediction among learners [3]. It is also recommended that augmented reality contributes to achieving 
happiness among students in the primary stage, which increases their motivation and ability to learn and read [4]. Based on the investigative process carried out by the researchers, the study problem of the study lies in investigating the effect of augmented reality in improving the visual thinking of 10th-grade students in mathematics in Jordan.

Due to the problem of the study, the following questions are articulated: What is the effect of augmented reality on developing visual thinking in mathematics among 10th-grade students in the Jerash governorate? The second question: What is the effect of augmented reality on the development of each of the visual thinking skills (visual reading skill, visual discrimination skill, scientific deduction skill, the skill of analyzing and interpreting the visual shape) in mathematics among 10th-grade students in Jerash governorate?

With that, the following objectives formatted to answer the questions of the study: Explore the effect of augmented reality on developing visual thinking in mathematics among 10thgrade students in Jordan and examine the effect of augmented reality on the development of each of the visual thinking skills (visual reading skill, visual discrimination skill, scientific deduction skill, the skill of analyzing and interpreting the visual shape) in mathematics among 10th-grade students in Jordan.

Given the significance of augmented reality technology in developing visual thinking among students who have learned to use it, the significance of this study lies in the scarcity of Arab and foreign studies that have investigated the effectiveness of augmented reality technology in visual thinking. Importantly, this study is the first at the level of Jordan and the third at the regional level investigating the increasing knowledge in the area of augmented reality and visual thinking and its effect on students. Accordingly, this paper presents an analysis of the effect of augmented reality in improving visual thinking in mathematics of 10th-grade students in Jordan.

\section{LITERATURE REVIEW}

In light of the nature of the study, it is necessary to demarcate the literature review into four parts as follows: use of augmented reality technology, visual thinking, visual thinking skills, and visual thinking tools.

\section{A. Use of Augmented Reality Arachnology}

Augmented reality technology is considered the product of the development of virtual reality, which is the integration of real reality with augmented information, whether it is still images, videos, or texts taking into account that real reality (RR) cannot be ignored to enhance the perception to develop visual thinking of the learner in mathematics. Augmented reality technology is distinguished from virtual reality in that augmented reality is the cutting-edge, easiest, and latest technology used in the educational learning process. Among its key characteristics are providing clear, flawless, and accurate information, the possibility of entering information easily and effectively, the ability to interact between the teacher and the learner in a positive, flexible, and less expensive manner. As put by [5], augmented reality provides an interactive environment that the real world does not offer.
Augmented reality also employs multimedia as digital content augmented with 2D and 3D animations or videos. Moreover, it is indicated that augmented reality takes into account individual differences among learners and is a safe way for children while the impact of learning with the learner's sense of fun [6]. This is confirmed by [4] that the animation used in augmented reality contributes to achieving educational objectives and furnished children with fun and happiness and that the appearance of 3-dimensional models while learning increases their motivation towards learning.

Augmented reality is characterized by the complementarity between the media based on this type of education, which aims to enhance and enrich the real world. The media-based augmented reality such as icons, printed images, and interactive videos contributes to raising the efficacy of academic achievement, allows students to control the presentation, and repeats the scenes that embody the information, ensuring the realization of the principle of visual analysis by controlling the speed of presentation [7]. The augmented reality contributes to achieving the highest degree of interaction between the scientific content and the learner, which is difficult to achieve in traditional learning, especially in learning abstract scientific concepts in mathematics, which are difficult for the learner to understand and perceive, as augmented reality contributes to the survival of the learning effect and the achievement of self-learning [8].

The concept of augmented reality is one of the up-to-date concepts and indicates that augmented reality has expanded in real reality by adding layers of computer-generated information to the real environment, and this information may be texts, videos, or static and animated graphics [9]. Likewise, it is asserted that augmented reality combines the virtual environment and the real environment in a 3-dimensional image for the user to see as a real-world [10]. Moreover, it is believed that augmented reality is a system that allows the integration between the real and the virtual world in the same place, where they interact together at the same time, as students use computers to attain rich environments and meaningful multi-media content related to the context of the educational content [11]. As specified by [12], the fundamental point is the difference between virtual augmented reality and augmented reality is immersion, as virtual augmented reality uses masks and special glasses that immerse the learners in learning and try to convince them that they are inside a real reality, so it is a reasonably convincing illusion, while augmented reality does not ignore the real world but uses a computer to improve it. Augmented reality technology is distinguished from virtual reality in that augmented reality is the cutting-edge, easiest, and latest technology used in the educational learning process [13]. Among its key characteristics are providing clear, flawless, and accurate information, the possibility of entering information easily and effectively, the ability to interact between the teacher and the learner in a positive, flexible, and less expensive manner. As put by [5], augmented reality provides an interactive environment that the real world has not provided.

Importantly, augmented reality provides an opportunity for students to interact with the educational content in general and in teaching and learning mathematics in particular because it 
includes abstract and complex scientific concepts, where augmented reality can simulate these concepts and embody the information and this is reflected in the development of thinking skills, especially visual thinking, which is one of the most complex types of thinking. This useful and practical aspect of augmented reality has been confirmed by previous studies, including [14] and [15]. Therefore, the development of thinking is one of the most important points that educational institutions focus on to achieve it among students by harnessing all their capabilities in developing thinking of students, which is reflected in students in the conscious and appropriate interaction with life and the circumstances surrounding it. Visual thinking is one of the types of thinking that is no less important than other types of thinking because it depends on the five senses that connect the person with the world around him and we cannot express it in writing [16]. As defined by [17], it is the merging of the senses with thinking to help in explaining a situation, and it is the greatest method of perception and has a direct impact on developing skills and acquiring competencies in teaching and learning. However, it is shown the effectiveness of augmented reality based on mobile learning in developing academic achievement and motivation in science subjects for fourth-grade students is on the rise [6]. As for the study [18], it evaluates student's achievement and motivation during a high school augmented reality math activity that focuses on dimensional analysis. The use of augmented reality in mathematics and a combination of print and augmented reality also known as interactive printing are demonstrated. Participants in the quasi-experimental study are 61 students and the study instruments are pre and postachievement tests. The results of the study have supported claims that the use of technology in a mathematics lesson and augmented reality increase student's achievement and enhance the student's motivation to learn mathematics and that the impact of technologies on the conceptual use of mathematics demonstrates the need for continued exploration to determine the impact of technologies not only on overall mathematical achievement but also on the specific type of conceptual mathematical activity.

The study aimed to benefit from the ability of virtual reality and augmented reality to visualize 3-dimensional shapes in mathematics where the study has investigated the possibility of using virtual reality and augmented reality techniques to teach the lesson of engineering solids to primary school children [19]. A 30-student sample randomly selected from fourth, fifth, and sixth grades is divided into three groups comprising a control group and two experimental groups. The results show that applying new technologies in teaching virtual and augmented reality improves interaction and students' interest in teaching mathematics, which contributes to increasing learning efficacy and understanding mathematical concepts when compared to traditional teaching methods.

This study identified the effect of augmented reality technology on the achievement of high school students in a unit in the science subject and their attitudes towards teaching the science subject [20]. To achieve the objectives of the study, the quasi-experimental approach is used, and the study is applied to a sample divided into two groups; an experimental group taught using augmented reality technology and a control group taught using the traditional method. The results show that students of the experimental group are more positive and happy about learning and want to continue to use augmented reality applications in the future. The results also conclude that the students show no signs of anxiety when using augmented reality applications. The trends of secondary school learners in Turkey towards augmented reality applications have been explored [21]. The study has also identified the relationship between the trend towards augmented reality and achievement in the solar system unit using augmented reality technology for 4 weeks. The results show that learners have positive trends towards augmented reality technology. They also show that there is a statistically significant relationship between the trend towards augmented reality and achievement. An analytical study of the results of (50) research papers in three databases, namely: Web of Science, Link Scopus, and Springer during 2008-2018 [22]. Factors such as the advantages, uses, challenges, and scope of augmented reality in the educational domain, and the positive or negative effects of its use in learning are analyzed to include students at various educational levels. After analyzing the results, it is concluded that the use of augmented reality for comprehensive education in mathematics is the area in which most studies have been conducted. The study recommends the necessity of conducting pieces of research in other areas of the importance of augmented reality in education.

\section{B. Visual Thinking}

Visual thinking is defined as one of the types of thinking that results from what we see around us, whether intentional or unintentional and it is the one that depends on the sense of sight because it is the means of communication that captures images and sends them to the mind and interacts with them, either by distinguishing, analyzing, interpreting or deducting. Visual thinking is constructed on experimental research into the way of thinking of learners by focusing on developing their abilities in changing and translating the visual language carried by the visual shape into verbal, written, or spoken language. This means that the relationship between the cognitive structure and the cognitive representation is a reciprocal relationship based on the influence and effect from the inside through which knowledge is strongly represented because visual representation supports visual thinking in terms of the ability to see the internal relationships of the presented shape and reveal the relative relationships in the dimensions of the shape and the development of inference skills [23].

In the same vein, the impact of augmented reality technology on teaching concepts related to the relationship between the earth and the sun to university students-majoring in geography has been identified [24]. The researchers have used the experimental approach on a 30-student sample from the University of Washington, where models designed with augmented reality technology are presented for the concepts under study. They have also employed worksheets as study instruments to evaluate the development of concepts among students applied pre and post the same group. The study shows that the students' understanding of realistic concepts related to the relationship between the earth and the sun greatly improves due to the effectiveness of models designed with augmented reality technology. Also, the study shows that the use of this 
technology contributes to replacing false alternative perceptions of concepts with correct concepts.

The effect of augmented reality and its ability to facilitate the learning of chemistry for students has been revealed so that they can understand abstract concepts [25]. The study has employed the semi-experimental approach on a 96-student sample majoring in organic chemistry at the University of Washington, where they are divided into three groups: (26) students taught through books only, (26) students taught through augmented reality only, and (22) students taught through augmented reality in cooperative pairs. The study instruments are represented in the questionnaire, a chemistry self-efficacy measure, and an achievement test. The study concludes that the performance of a group of students taught using augmented reality only does much better than students taught without using augmented reality, and other students taught using augmented reality in cooperative pairs. The study recommends the need to support education with augmented reality technology in various educational stages other than the university stage.

\section{Visual Thinking Skills}

There is a multiplicity of visual thinking skills and differs from one study to another according to the nature of the educational situation, as the skills of visual thinking are demonstrated in the following: the skill of visual reading, the skill of visual discrimination, the skill of perceiving spatial relations, and the skill of visual closure [26]. It is asserted that the skills of visual thinking can be summarized as follows: the skill of describing and recognizing the shape, the skill of analyzing and interpreting the shape, the skill of correlating relationships in the shape, the skill of perceiving and clarifying ambiguity, and the skill of inferring meanings [27]. Abd AlReda and Fadel (2019) also maintain that the skills of visual thinking are demarcated into the skill of visual reading which is the ability to determine the dimensions and nature of the shape or image presented [28]. It is also the lowest skill of visual thinking skills, the skill of visual discrimination which is the ability to recognize the shapes or images and distinguish them from other shapes or images, the skill of scientific deduction which is the ability to attain new meanings and arrive at scientific concepts and principles through the presented shape, image, or map, and the skill of analyzing and interpreting the visual shape which is the ability of the individual to focus on minute details, pay attention to macro and microdata, and clarify the meanings of shapes, words, symbols, signs and figures, and approximate relations among them.

\section{Visual Thinking Tools}

At a time when the visual thinking skills are numerous, their tools are also numerous, as the modern digital tools that supported it help and work to capture ideas and organize information, as elucidated by the study of [29]. Visual symbols are likened to three tools: pictures which are one of the most accurate tools in communication, and they are a visual symbolic component of ideas and reality, symbols which are the most widely used and widespread tools in communication, and they are all indications of something and its proxy, and diagrams of shapes which illustrate an idea, are expressed in simple shapes or expressed in lines and include drawings related to pictures, concepts, and comics. Visual thinking is constructed on experimental research in the way of thinking of learners by focusing on developing their capabilities in changing and translating the visual language carried by the visual shape into a verbal language, written or spoken to develop communication skills and creative and logical thinking skills that achieve the learner's confidence in dealing with complex, ambiguous, and diverse opinions. Likewise, these skills enhance perception through discussions that take place across its processes to develop aesthetic practice [30].

Additionally, the ability to think visually overlaps with the skill of critical thinking that helps in solving problems and comprehend concepts, and at long last, visual thinking is seen as a more complex mental activity than the rest of the levels of thinking, as it depends on the representation of the displayed figure with symbols, diagrams, and pictures. Thus, visual thinking is one of the most important matters in the educational learning process as specified by [31] indicating the importance of teaching visual thinking skills to the learner because it works to raise the level of the learner's ability to communicate with others and increase mental ability. Visual thinking skills are regarded as a key to different types of thinking, including innovative thinking and critical thinking. The role of visual thinking skills in raising the level of motivation among the learners is unforgettable, and this is what encourages learners to teach and learn, works to develop science processes such as observation, interpretation, and analysis, helps them to selflearning that takes into account the individual differences between them and also assists to achieve objectives of science such as interpretation and prediction.

Both [28] indicate that there is great importance for visual thinking and its effect on the educational process, as it has replaced a lot of verbal information in pictures and visual shapes, the most important of which is the learner's ability to develop visual language skills and comprehend all visual messages surrounding individuals inside the classroom, which indicates the scientific and technological development. Also, it can be emphasized that visual thinking is of great importance for people in general and for learners in particular in expanding their perceptions of understanding and imagination, and this helps them speed up the process of understanding and validating the information and facilitating its retrieval [32].

The educational theories in the area of educational technology have emphasized the importance of using visual thinking and its various tools such as images, shapes, diagrams, and graphs in the education process as the most important theory that focuses on the importance of using graphics in the education process is the theory of information processing. As put by [33] based on the learning styles used by the learner, thinking is classified into (Visual-Aural-Kinesthetic Model) which is auditory thinking, emotional thinking, and visual thinking. Visual thinking in the previous classification mentioned by [33], explained in detail by [34], and graphically represented by [35] helps in transferring the information to the human brain and processing inside it, and then expressing it in various methods. It turns out that the sense of sight controls the largest amount of information transferred to the brain, which indicates that thinking that depends on the sense of sight and is called visual thinking is the most used and the most important 
among the thinking styles in this classification. As defined by [36], visual thinking is an individual's skill to visualize and present an idea or information using pictures and drawings instead of the much stuffing and redundant wordiness used in communication.

Visual thinking skills are considered three main skills, namely vision, visualization, and drawing, where sub-skills branch out of these three main skills, and this is what [37] emphasized, as the three main skills are the origin of all skills and sub-skills change according to the types of sciences that belong to them. The visual sub-skills of computer science, for example, are different from the visual sub-skills of mathematics. Among the studies examining augmented reality and its effect on visual thinking is [38], which has investigated the effectiveness of a program based on augmented reality technology in developing visual thinking skills in science subjects for 9th-grade students in Gaza. Due to the nature of the study, the experimental method has been used. The study instrument is a one-group design with a pre-post measurement, where the study population consists of all the 6894 9th-grade students in schools of the Ministry of Education in the Gaza Strip. The Yarmouk Basic School (A) for boys in Gaza Governorate is randomly selected, and one class is also randomly selected, as the study sample consists of (43) students from the 9th-grade school. The study shows that there are statistically significant differences at the level of $(\alpha=0.01)$ between the average scores of the students in the pre and post applications on the visual thinking test. The study also shows that the employment of the program based on augmented reality technology achieves high effectiveness (Black's Modified Gain Ratio = 1.2) in developing visual thinking skills.

Against this, based on the importance of the primary stage among the stages of the educational process, the use of augmented reality technology has an effective effect on expanding the students' perceptions of visualization and visual thinking. Therefore, the basic 10th-grade students are selected to teach them mathematics because this subject is the closest to reality, needs sensory experiences, and focuses on developing students' thinking skills in general and visual thinking in particular. Intending to investigate the effect of augmented reality technology on visual thinking, augmented reality hopefully has great importance and effectiveness in the development of the educational learning process, as it is expected to provide an interactive learning environment filled with vitality, positivity, and excitement.

\section{RESEARCH METHODOLOGY}

Due to the nature of the study, the quasi-experimental approach is used for its suitability for the study. The independent variable (augmented reality technology) is subjected to test and its effect on the dependent variable (visual thinking) is measured for the students of the experimental group.

\section{A. Study Sample}

The study sample is purposefully selected from Jerash Model Schools of the Education Directorate of Jerash Governorate. The study sample consists of (57) male and female students randomly distributed into two sections: one of them is experimental taught using augmented reality technology and consists of (28) male and female students, and the second is the control group taught by the traditional method and consists of (29) male and female students.

\section{B. Study Instrument, Validity and Reliability}

The study instrument comprises a visual thinking test consisting of (20) items of a multiple choice of geometry unit in mathematics for the 10th grade of the academic year (2020/2021). This test is prepared and developed by researchers of the paper, where four skills are identified: visual reading skill, visual discrimination skill, scientific deduction skill, the skill of analyzing and interpreting the visual shape. A specification table is prepared and illustrated in Table I.

TABLE I. SPECIFICATIONS FOR THE VISUAL THINKING TEST

\begin{tabular}{|l|l|l|}
\hline Skill & $\begin{array}{l}\text { Number of } \\
\text { Questions }\end{array}$ & Percentage (\%) \\
\hline Reading skill & 5 & $25 \%$ \\
\hline Visual discrimination skill & 6 & $30 \%$ \\
\hline Scientific deduction skill & 5 & $25 \%$ \\
\hline $\begin{array}{l}\text { Skill of analyzing and interpreting } \\
\text { the visual shape }\end{array}$ & 4 & $20 \%$ \\
\hline Total & 20 & $100 \%$ \\
\hline
\end{tabular}

To verify the validity of the test (apparent and content), it is presented in its initial form to a group of 10 experienced and specialized validators, and their observations are strongly considered. Also, the reliability of the test is verified by applying the test to the reliability sample outside the study sample, consisting of (31) male and female students through the calculation of the Kuder-Richardson 20 (KR-20) reliability coefficient, and the Test-Retest Reliability coefficient, and the results of the analysis are shown in the table.

Table II shows that all the values of reliability coefficients are high, enhancing the accuracy of the instrument and its suitability for application to achieve the purposes of the study.

TABLE II. RESULTS OF RELIABILITY COEFFICIENTS ANALYSIS

\begin{tabular}{|l|l|l|}
\hline \multirow{2}{*}{ Study Instrument } & \multicolumn{2}{|l|}{ Calculated Reliability Coefficient } \\
\cline { 2 - 3 } & Kuder-Richardson 20 (KR-20) & Test-Retest \\
\hline Achievement Test & 0.923 & 0.931 \\
\hline Visual Thinking Test & 0.961 & 0.934 \\
\hline
\end{tabular}

\section{RESUlTS AND DISCUSSION}

Results and discussion of the first question of the study "What is the effect of augmented reality on developing visual thinking in mathematics among 10th-grade students in Jerash governorate?”

To answer the first study question, the values of the arithmetic means and standard deviations of the performance of the two groups (experimental and control) in the pre and post-performance are calculated. Table III shows the results of the analysis. 
Table III show that there is a noticeable convergence between the two groups in the pre-performance of visual thinking skills, while there are apparent differences between the two groups in the post-performance of visual thinking skills, as it is noticed that the value of the post arithmetic means of the performance of the experimental group students is (18.50) which is the highest compared to the post arithmetic mean of the performance of the control group students which is (11.50).

This result is due to the effect of augmented reality technology in developing visual thinking in the teaching of the geometry unit for several reasons, including the technology's ability to display the model and check it from all directions and its movement, which has helped students attain the approximate sense of realism. This technology also assists to attract students' attention, as it is accompanied by sounds, videos, colors, and 3-dimensional images enhanced with information and concepts related to pictures, which helps in developing visual thinking skills, allowing interaction with the application individually or collectively and giving them sufficient opportunity for visual thinking, and positively increasing their interaction. Importantly, the application helps in providing images of geometric shapes that are unavailable in the 10th-grade textbook, which broadens the perceptions of thinking in general among the students. The positive result of the current study in bringing about diversity and a paradigm shift in favor of the use of augmented reality technology in visual thinking is consistent with the results of many studies, including the studies of [24], [25], and [39] that have investigated the effectiveness of a program based on augmented reality technology in developing the students' achievement.

Results and discussion of the second question of the study "What is the effect of augmented reality on the development of each of the visual thinking skills (visual reading skill, visual discrimination skill, scientific deduction skill, the skill of analyzing and interpreting the visual shape) in mathematics among 10th-grade students in Jerash governorate?”
Table IV shows the values of the arithmetic means and standard deviations of the performance of the members of the experimental group in the pre-and post-test according to each skill.

It is evident from the results of the analysis of Table IV that the values of the arithmetic means of the performance of the members of the experimental group in the post-test are high (4.00 -5.20) in all skills compared to their performance in the pretest. The visual discrimination skill is ranked first with an arithmetic mean of (5.20) and a standard deviation of (0.76), while the visual reading skill is ranked second with an arithmetic mean of (4.73) and a standard deviation of (0.52). Also, the scientific deduction skill is ranked third with an arithmetic mean of (4.57) and a standard deviation of (0.50). As for the last rank, it is the skill of analyzing and interpreting the visual shape with an arithmetic mean of (4.00) and a standard deviation of (0.00).

To find out the indications of the differences between the arithmetic means of skills, the Analysis of Covariance (ANCOVA) is used as illustrated in Table V.

The results mentioned in Table $\mathrm{V}$ show that there is a difference in the post-performance between the two groups, where all the values of $(F)$ are statistically significant at the level of $(\alpha=0.05)$. In detail, the difference is in favor of the experimental group, as the arithmetic means of their performance in the visual thinking skills test are higher compared to the arithmetic mean of the performance of the control group. The value of the practical significance of the combined visual thinking skills is (0.674). This indicates that (67.4\%) of the variance between the two groups is due to the effect of the experiment. This result is to the fact that visual thinking is a mental capacity associated with the visual perceptual aspects, where it occurs when there is mutual harmony between what the learner sees in terms of shapes, drawings, and relationships, and what happens in terms of linking and mental output based on seeing the presented drawing and this is what the augmented reality technology focuses on, and this is what is confirmed by [23] and [26].

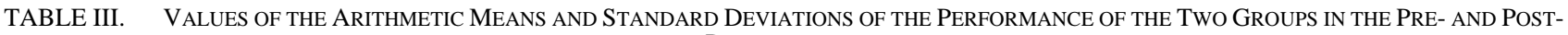
PERFORMANCE

\begin{tabular}{|l|l|l|l|l|l|l|l|}
\hline \multirow{2}{*}{ Visual Thinking Skills } & \multirow{2}{*}{ Group } & \multirow{2}{*}{ Sample Size } & \multirow{2}{*}{$\begin{array}{l}\text { Number of } \\
\text { Items }\end{array}$} & & \multicolumn{2}{|l|}{ Pre-Performance } & \multicolumn{2}{l|}{ Post-Performance } \\
\cline { 5 - 9 } & & & AM & SD & AM \\
\hline \multirow{2}{*}{ Total Performance } & Experimental & 30 & 20 & 11.43 & 7.30 & 18.50 \\
\cline { 2 - 8 } & Control & 30 & 11.07 & 7.09 & 11.50 \\
\hline
\end{tabular}

TABle IV. Values of the Arithmetic Means and Standard Deviations ArRanged in Descending Order Due to the ARithmetic Means

\begin{tabular}{|c|c|c|c|c|c|}
\hline \multirow[b]{2}{*}{ Visual thinking skills } & \multicolumn{2}{|c|}{ Pre-Performance } & \multicolumn{2}{|c|}{ Post-Performance } & \multirow{2}{*}{ Evaluatior } \\
\hline & $\mathrm{AM}$ & SD & $\mathrm{AM}$ & SD & \\
\hline Visual discrimination skill & 1.43 & 0.86 & 5.20 & 0.76 & High \\
\hline Visual reading skill & 1.70 & 1.49 & 4.73 & 0.52 & High \\
\hline Scientific deduction skill & 1.50 & 0.78 & 4.57 & 0.50 & High \\
\hline $\begin{array}{l}\text { The skill of analyzing and interpreting the } \\
\text { visual shape }\end{array}$ & 1.83 & 1.05 & 4.00 & 0.00 & High \\
\hline Total Performance & 11.07 & 7.09 & 18.50 & 1.43 & High \\
\hline
\end{tabular}


TABLE V. RESUlts of the Associated ANALysis of COVARIANCE (ANCOVA)

\begin{tabular}{|c|c|c|c|c|c|c|}
\hline Source of Variance & Sum of Squares & Degree of Freedom & Average of Squares & Value of F & Level of Sig. & Eta $=$ Squared \\
\hline \multirow{4}{*}{ Visual Reading Skill } & 0.067 & 1 & 0.067 & 0.074 & & \multirow{4}{*}{0.695} \\
\hline & 117.544 & 1 & 117.544 & 129.679 & $0.000 *$ & \\
\hline & 51.666 & 57 & 0.906 & & & \\
\hline & 169.333 & 59 & & & & \\
\hline \multirow{4}{*}{ Visual Discrimination Skill } & 1.328 & 1 & 1.328 & 1.203 & & \multirow{4}{*}{0.624} \\
\hline & 104.495 & 1 & 104.495 & 94.636 & $0.000 *$ & \\
\hline & 62.939 & 57 & 1.104 & & & \\
\hline & 170.933 & 59 & & & & \\
\hline \multirow{4}{*}{ Scientific Deduction Skill } & 0.699 & 1 & 0.699 & 1.052 & & \multirow{4}{*}{0.649} \\
\hline & 69.952 & 1 & 69.952 & 105.294 & $0.000 *$ & \\
\hline & 37.868 & 57 & 0.664 & & & \\
\hline & 108.983 & 59 & & & & \\
\hline \multirow{4}{*}{$\begin{array}{l}\text { The skill of analyzing and } \\
\text { interpreting the visual } \\
\text { shape }\end{array}$} & 1.569 & 1 & 1.569 & 3.019 & & \multirow{4}{*}{0.564} \\
\hline & 38.4 & 1 & 38.4 & 73.869 & $0.000 *$ & \\
\hline & 29.631 & 57 & 0.52 & & & \\
\hline & 69.6 & 59 & & & & \\
\hline \multirow{4}{*}{ Total Performance } & 11.957 & 1 & 11.957 & 1.931 & & \multirow{4}{*}{0.674} \\
\hline & 729.659 & 1 & 729.659 & 117.806 & $* 0.000$ & \\
\hline & 353.043 & 57 & 6.194 & & & \\
\hline & 1100.000 & 59 & & & & \\
\hline
\end{tabular}

The way of thinking of students who have learned with augmented reality focuses on developing their abilities in translating the visual language embedded in the visual shapes presented in the lessons into verbal written or spoken language, developing communication skills that achieve the learner's confidence in dealing with complexity, ambiguity, and diversity of opinions, as well as increasing and enhancing perception through discussions that take place across their operations to develop aesthetic practice, and this will help in developing the visual thinking skills, and this is confirmed by [38] and [39]. The information offered in the study unit (geometry) in the textbook of the 10th grade has helped to develop the visual reading skill among the students of the experimental group represented by the ability to determine the dimensions and nature of this shape on the one hand. On the other hand, it has helped students to perceive the shape and distinguish it from other shapes and this represents the development of the visual discrimination skill, and this is confirmed by [17]. The development of the scientific deduction skill is represented by the ability of students to attain new meanings and scientific concepts and principles through the shape. Students learn, through this technology, to focus on the minute details, pay attention to geometric shapes and the subject of the study unit, and get geometric properties through their shapes. The augmented reality technology has its effect on the visual representation of ideas from shapes and drawings as an incentive for students to discover the meaning of the presented contents in the front of them, and this leads to better thinking, a progressive development towards creativity, and an indication of the conceptual developmental structure. Reading the visual shape aims to understand the meaning and includes understanding in reading the shape, linking, symbol, meaning, and organizing the read ideas. Reading the visual shape is a set of activities that allow the analysis of the information given in the form of conceptual connections in the presented shape, that is, a set of activities linking new information with previously acquired data stored in memory as these understanding models are closely related to the representation of the presented shape and or drawing.

\section{CONCLUSION}

The current study investigates the effect of augmented reality in improving visual thinking of 10th-grade students in mathematics in Jordan. In light of the results of the study, the objectives of the study, i.e. exploring the effect of augmented reality on developing visual thinking in mathematics among 10th-grade students in Jordan and examining the effect of augmented reality on the development of each of the visual thinking skills (visual reading skill, visual discrimination skill, scientific deduction skill, the skill of analyzing and interpreting the visual shape) in mathematics among 10th-grade students in Jordan have been achieved. Thus, the current study recommends using augmented reality technology in education in general, and in mathematics education in particular, organizing the content of mathematics curricula in line with augmented reality technology, which helps in developing visual thinking skills, paying attention to designing electronic lessons in mathematics and producing them using augmented reality applications, and holding training courses for mathematics teachers and encouraging them to learn how to integrate technology with education and develop visual thinking. 


\section{FUTURE WORKS}

The area of augmented reality needs to be extended in other current works, with new approaches in the future work. This domain can be applied in other scientific areas such as physics or other detailed issues in mathematics.

\section{ACKNOWLEDGMENTS}

The author is grateful to the Middle East University, Amman, Jordan for the financial support granted to cover the publication fee of this research article.

\section{REFERENCES}

[1] Catenazz, N. \& Sommaruga, L. (2013). Social media: challenges and opportunities for education in modern society, mobile learning and augmented reality: new learning opportunities, International Interdisciplinary Scientific Conference, Vol. 1 No1.

[2] Christie, Rodgers. (2014). Augmented reality books and the reading motivation of fourth-grade students, Union University School of Education, UMI. ProQuest LLC.

[3] Klopfer, E. (2008). Augmented learning: Research and design of mobile educational games. Cambridge, MA: MIT Press.

[4] Rabia M. Yilmaz and SevdaKucuk, YukselGoktas. (2015). Are augmented reality picture books magic or real for preschool children aged five to six? British Educational Research Association. Journal of Educational Technology and Society, 2(7). 22-36.

[5] S. Cuendet, Q. Bonnard, S. Do-Lenh, and P. Dillenbourg. (2013). Designing augmented reality for the classroom. Computers and Education, 68(2), 557-569.

[6] Chiang, T., Yang, S. \& Hwang, G. (2014). An augmented reality-based mobile learning system to improve student's learning achievements and motivations in natural science inquiry activities. Educational Technology \& Society, 17 (4), 352-365.

[7] Wang, J. \& Hartley, K. (2003). Video technology as a support for teacher education reform. Journal of Technology and Teacher Education, 11(1), 105-138.

[8] Derry, S.J. (2007). Guidelines for Video Research in Education: Recommendations from an Expert Panel. Chicago: Data Research and Development Center.

[9] Glockner, H., Jannek, K., Mahn, J., and Theis, B. (2014). Augmented reality in logistics: Changing the way we see logistics: A DHL perspective.

[10] Bower, M., Howe, C. (2018). Augmented reality in education. Educational Media International, 51(1), 15-1.

[11] M. AKC, Ayır and G. Akc, Ayır. (2017). Advantages and challenges associated with AR for education: A systematic review of the literature. Educational Research Review, 20(3).

[12] Kulkarni, S. \& Takawale, N. (2016). Comparative Study of Augmented Reality and Virtual Reality. International Journal of Innovative Research in Computer and Communication Engineering, 4 (1): 1-6.

[13] Liarokapis, F., Anderson, E. (2010). Using augmented reality as a medium to assist teaching in higher education. In Proceedings of the 31st Annual Conference of the European Association for Computer Graphics (Euro graphics 2010), Education Program (pp. 9-16). Norrköping, Sweden: Euro graphics Association.

[14] Ivanova, M, \& Ivanov, G. (2011). Enhancement of learning and teaching in computer graphics through marker augmented reality technology. International Journal on New Computer Architectures and Their Applications, (IJNCAA), 1(1), 176-184.

[15] Núñez, M., Quirós, R., Núñez, I., Carda, J. B., Camphor, E., Mauri, J. L. (2008). Collaborative augmented reality for inorganic chemistry education. WSEAS International Conference. Proceedings-Mathematics and Computers in Science and Engineering. Hera lion, Greece: ACM Digital Library.

[16] Dilek, G. (2010). Visual thinking in teaching history: Reading the visual thinking skills of 12-year-old pupils in Istanbul. Education, 38(3), 257274. ERIC Document Reproduction Service No. EJ898020.
[17] Carrascals. S. (2019). Acquisition of competencies for sustainable development through visual thinking. A study in rural schools. Sustainability, 11(8), 23-37 Https://doi.org/10.3390/su11082317.

[18] Estapa, A.T. and Nadolny, L.N. (2015). The effect of augmented reality enhanced mathematics lessons on student achievement and motivation. Journal of STEM Education: Innovations and Research, 16(3), 40-48. ERIC Document Reproduction Service No. EJ1078415.

[19] Demitriadou, E., Stavroulia, K.E. and Lanitis, A. (2019). Comparative evaluation of virtual and augmented reality for teaching mathematics in primary education. Education and Information Technologies, 25, (2), 381-401. Https://doi.org/10.1007/s10639-019-09973-5.

[20] Sahin, D. and Yilmaz, R.M. (2020). the effect of Augmented Reality Technology on middle school students' achievements and attitudes towards science education. Computer Education, 144(2), 10-22. Https://doi.org/10.1016/j.compedu.2019.103710.

[21] Sirakaya, M., \& Cakrnak, E. K. (2018). Investigating student's attitudes toward Augmented Reality. MOJET: Malaysian Online Journal of Education Technology 1(6).

[22] Quintero J, Molera C, Juamperez J, Redecillas S, Meavilla S, Nuñez R, García-Volpe C, Del Toro M, Garcia-Cazorla Á, Ortega J, Segarra Ó, de Carpi JM, Bilbao I, Charco R. (2019). Augmented reality in educational inclusion. A systematic review on the last decade; 10: 1835. Doi: 10.3389/fpsyg.2019.01835.

[23] Saqr, Nasih, Hussein Salem. (2018). the effectiveness of using visual thinking networks in the development of visual thinking skills and academic achievement in mathematics for children with learning difficulties at the primary stage. Journal of Educational Sciences, 26(1), 210-247.

[24] Shelton, B., \& Hedley, N. (2010). Using augmented reality for teaching earth-sun relationships to undergraduate geography students. In The - 476 - First IEEE International Augmented Reality Toolkit Workshop, Darmstadt, Germany, IEEE Catalog Number: 02EX632 ISBN: 0-78037680-3. DOI: 10.1109/ART.2002.1106948.

[25] Chen, Y. (2013). Learning protein structure with peers in an ar enhanced learning environment. [Ph.D. Thesis]. The University of Washington. The USA.

[26] Suleiman, Mohamed El-Sayed. (2018). the effectiveness of a multimedia program based on the systemic approach according to the Davis model in developing visual thinking skills and cognitive achievement among hearing-impaired students. International Educational Specialized Journal, 7(4), 1-21.

[27] Jabr, Yahya Saeed. (2010). the effect of employing the strategy of the metacognitive learning course on the development of concepts and visual thinking skills in the sciences for the tenth primary students. [Unpublished Master Thesis]. College of Education, Islamic University, Gaza, Palestine.

[28] Abd Al-Reda, Athraa Abd al-Rahim, and Fadel, Sri Muayad. (2019). Visual thinking among students at College of Education of Waist University. The 11th International Scientific Conference, April/2019 at Waist University, Iraq.

[29] Abdulaziz, Safwat Hassan. (2018). The effect of using info graphics in teaching science on achievement and development of visual thinking skills and attitude towards them among elementary school students in the State of Kuwait. Concept Journal of In-depth Psycho-Philosophical and Humanistic Studies, 2(2), 42-63.

[30] Haciomeroglu, E. \& Chicken, E. (2012). Visual Thinking and Gender Differences in High School Calculus. International Journal of Mathematical Education in Science and Technology, 43(3), 303-313. ERIC Document Reproduction Service No. EJ992909.

[31] Razooqi, Raad Mahdi and Abdul Karim, Soha Ibrahim. (2015). Thinking and its Patterns, 1st Edition Amman: Dar Al-Masirah.

[32] Genovesi, J. S. (2011). An exploratory study of a new educational method using live animals and visual thinking strategies for natural science teaching in museums. Ph.D. Dissertation]. Drexel University, ProQuest.

[33] Sword, L. (2005). The Power of Visual Thinking. Gifted and Creative Services Australia, Retrieved Dec 26, 2020 from http://www.starjump.com.au/. 
[34] Thomas F. Hawk \& Amit J. Shah. (2007). Using Learning Style Instruments to Enhance Student Learning, Decision Sciences Journal of Innovative Education, Vol 5 NO. $1 . \quad$ DOI: 10.1111/J.15404609.2007.00125.X.

[35] Eicher, J.; Johns, J.; \& Bearley, W. (2009). Neuron-Linguistic Communication Profile Online. HRDQ Assessment Center. Retrieved Oct 25, 2020, from http://www. hrdqstore.com/assets/images/products/NCP/NeurolinguisticCommunicati on-Profile-Online-Assessment-Sample-Report.pdf.

[36] Wileman, R. E. (2000). Visual Communicating, Englewood Cliffs, NEducational Technology Publication, Biscoe Electronic.
[37] Grandin, T. (2006). Thinking in Pictures. Retrieved from http://www.grandin.com/inc/visual.thinking.html on Oct 25, 2020.

[38] Ahmad, Awadallah. (2016). the effectiveness of a program based on augmented reality technology in developing visual thinking skills in science subjects among ninth-grade students in Gaza. [Unpublished Master Thesis]. Al-Azhar University, Gaza, Palestine.

[39] Issa, Sami Abdul Hamid Muhammad. (2018). The use of mobile augmented reality technology with various support patterns (fixed/flexible) in developing some visual thinking skills among middle school students. Education Technology: Studies and Research, 37, (2), 151-193. 